\title{
ADMINISTRAÇÃO DISCURSIVA: UMA NOVA PERSPECTIVA PARA AS BIBLIOTECAS UNIVERSITÁRIAS BRASILEIRAS
}

\author{
DISCURSO DE LA GESTIÓN: UNA NUEVA \\ PERSPECTIVA PARA LAS BIBLIOTECAS DE LAS \\ UNIVERSIDADES BRASILEÑAS
}

\begin{abstract}
Simone Faury Dib - simonefdib@gmail.com Mestre em Ciência da Informação no Instituto Brasileiro de Informação em Ciência e Tecnologia (IBICT). Bibliotecária da Universidade Estadual do Rio de Janeiro (UERJ).
\end{abstract}

II.

Clóvis Ricardo Montenegro de Lima - clovis.mlima@uol.com.br Pós-doutor em Ciência da Informação pelo Instituto Brasileiro de Informação em Ciência e Tecnologia (IBICT). Pesquisador adjunto do IBICT.

\section{RESUMO}

Introdução: Neste artigo é apresentada visão geral sobre as bibliotecas universitárias na sociedade contemporânea, abordados os pressupostos básicos relacionados à administração discursiva e reveladas as formas de administração utilizadas nessas bibliotecas, divulgadas no Seminário Nacional de Bibliotecas Universitárias (SNBU).

Objetivo: Embasar a proposta de administração discursiva nas bibliotecas universitárias brasileiras, como alternativa às formas vigentes.

Metodologia: Investigação das formas de administração utilizadas nas bibliotecas universitárias brasileiras, na sociedade contemporânea, divulgadas no Seminário Nacional de Bibliotecas Universitárias.

Resultados: Apresenta diretrizes gerais para adoção da administração discursiva nas bibliotecas universitárias.

Conclusões: A administração discursiva constitui-se em alternativa possível e interessante, coerente com as demandas da sociedade contemporânea e que pode contribuir para 0 
desenvolvimento das pessoas, a racionalização dos processos organizacionais, a aprendizagem e a inovação.

Palavras-chave: Habermas. Biblioteca universitária. Administração de bibliotecas. Administração discursiva. Teoria do agir comunicativo. Ética do discurso.

\section{INTRODUÇÃO}

A transição da sociedade industrial para a sociedade da informação provoca mudanças econômicas, sociais e políticas. Nesse novo cenário, que privilegia um modelo de produção mais flexível, a multidisciplinaridade, a criatividade, a proatividade, a otimização do tempo de resposta, a não delimitação de fronteiras "espaciais" e, principalmente, a valorização do trabalho intelectual e das habilidades das pessoas, a informação e o conhecimento são considerados recursos fundamentais para 0 crescimento econômico e social.

A biblioteca universitária, organização vinculada a uma organização maior - a universidade -, também se enquadra nesse contexto. Dessa forma, dela são requeridas novas estratégias de ação que favoreçam sua adequação à nova realidade e permitam, por exemplo, acompanhar os avanços tecnológicos, desenvolver iniciativas que atendam às demandas dos usuários, procurando sempre estar em consonância com as diretrizes da universidade mantenedora e promover a interação e a colaboração no ambiente de trabalho.

É fundamental que a forma de administração utilizada na biblioteca valorize a comunicação tanto interna quanto externa, ou seja, entre todos os membros da biblioteca, entre estes e seus superiores, usuários e parceiros.

A forma de administração não deve se restringir ao enfoque funcionalista/instrumental, mas valorizar a interação efetiva entre os indivíduos, viabilizando a criação e a manutenção de vários canais de comunicação abertos e possibilitando que os habituais canais verticais de comunicação sejam complementados pelos canais horizontais e diagonais (BARAÑANO, 2005). A comunicação interna eficiente favorece a comunicação externa, tornando-a adequada e produtiva. O resultado é a cooperação, a aprendizagem contínua e a inovação. Entretanto, para que esse processo seja pleno, é fundamental o respeito à diversidade e à pluralidade cultural, e que todos os membros da organização possam efetivamente participar da tomada de decisão, sem qualquer tipo de coação. Essa mudança de perspectiva é o diferencial que certamente 
favorecerá o acompanhamento das novas tendências e, consequentemente, a adequação das bibliotecas universitárias brasileiras ao novo cenário. Assim, a administração discursiva, abordagem crítica da Administração a partir das teorias do Agir comunicativo e do Discurso de Jürgen Habermas, constitui-se em alternativa interessante para as bibliotecas universitárias brasileiras, uma vez que pode ser considerada uma forma de administração que valoriza a relação intersubjetiva entre todos os indivíduos, de forma igualitária, e prioriza a tomada de decisão coletiva e consensual, sem qualquer tipo de coação, possibilitando a aprendizagem, a melhoria de processos e a inovação.

\section{UNIVERSIDADE E BIBLIOTECA UNIVERSITÁRIA}

Segundo Prestes (1996, p. 105), a educação pode ser considerada uma ação social entre sujeitos que acontece "[...] sob o thelos do diálogo, em processo interativo, onde a constituição do sujeito se dá pela ação comunicativa entre os homens." Desta forma, "[...] a recuperação da educação, enquanto formadora do homem como sujeito de ação cognitiva, ética e política só se efetiva sob a rubrica de uma razão capaz de produzir entendimento."

Nesse cenário, a universidade, que cumpre papel determinante na sociedade contemporânea, seja exercendo a função precípua de ensino na formação de cidadãos e de profissionais para o mercado de trabalho, seja nas funções de pesquisa e extensão, é pressionada a se adequar às demandas da atualidade.

Conforme destaca Dias Sobrinho (2005a, p. 29), a permanência da universidade como instituição macrossocial imprescindível é justificada em virtude de "[...] sua grande capacidade de preservar sua solidez estrutural e de se renovar continuamente, sem, entretanto, se desnaturar ou afastar-se dos seus princípios naturais." Essa solidez, que permitiu a sobrevivência da universidade ao longo de séculos, deve-se a duas características contraditórias:

De um lado a universidade guarda uma forte tendência a resistir às mudanças e de assegurar a unidade, por outro lado ela apresenta grande flexibilidade, capacidade de adaptação às mudanças que vão surgindo e abertura à diversidade. A universidade tem sobrevivido a todas as mudanças sociais porque, ainda que erre e falhe, tem enorme capacidade de se superar, de se adaptar, de se transformar e de pensar o futuro (DIAS SOBRINHO, 2005a, p.29-30). 
A emergência das tecnologias de informação e comunicação e a globalização são aspectos importantes que afetam as universidades na sociedade contemporânea. Sobre a influência das novas tecnologias, destaca-se o ponto de vista de González de Gómez (2011, p. 237), no qual afirma que "A reconstrução argumentativa de uma universidade plural e comunicativamente interativa, teria que atender a condições e possibilidades que vão além das infra-estruturas de acesso." A autora destaca o fato de que, ao mesmo tempo em que as tecnologias de informação e comunicação favorecem o surgimento de novas formas de "[...] reunião de saberes e pessoas, geram também novas formas de dispersão, novas polifonias, novas formas em que os quadros normativos ficam obscurecidos pelas novas expressões polinômicas de redes sem fronteiras institucionais." Dessa forma, a universidade, na perspectiva de González de Gómez (2011, p. 237), deve manter

[...] suas funções de provisão de recursos aos mundos da vida, através da formação e de diferentes funções e atividades, mas principalmente, através de espaços públicos constituídos no interior dos diferentes campos disciplinares, e desde onde a Universidade estabelece uma comunicação pública, plural e dispersa com a sociedade.

A globalização, por sua vez, além de provocar transformações na economia, no comércio e na cultura, afeta o ensino superior e a universidade. Como ressalta Dias Sobrinho (2005b, p. 169) "[...] nos países de industrialização avançada, induz novos temas e práticas de pesquisa, difunde rápida e amplamente os resultados e aplicações das investigações." Essas mudanças impactam os pesquisadores e sua relação com a ciência e a sociedade. Dias Sobrinho (2005b, p. 169) destaca três aspectos, nesse sentido, que considera relevantes:

O primeiro é o quantitativo: nos últimos cinqüenta anos, e de modo crescente, a humanidade vem apresentando um acúmulo de conhecimentos incomparavelmente superior a qualquer outro período. Uma segunda observação diz respeito a uma mudança na esfera da produção dos conhecimentos, especialmente caracterizada por uma tendência de passagem da ciência básica, muitas vezes da pesquisa desinteressada, para os contextos de aplicação e de controle do conhecimento. O impacto disso, e esse é o terceiro aspecto, é muito grande tanto nas esferas mais alargadas quanto nas microdimensões da vida.

A educação superior, na concepção de Dias Sobrinho (2005b, p. 170), constitui-se em patrimônio público quando "[...] exerce funções de caráter político e ético, muito mais 
que uma simples função instrumental de capacitação técnica e treinamento de profissionais para as empresas." O autor acredita ser fundamental que a educação superior

[...] produza conhecimentos e formação com um grande sentido de pertinência social. Por meio do conhecimento e do trabalho de formação, sem abdicar de suas competências críticas, ela deve desenvolver à capacidade de resposta às demandas e às carências da sociedade. A pertinência requer autonomia para identificar as prioridades e o conteúdo social das carências e demandas. Isso exige uma ampla participação de estudantes, professores e pesquisadores na definição de prioridades sociais e na produção e socialização do conhecimento rigoroso e adequado. [...] é preciso instaurar uma ética da responsabilidade social que vincule os atores acadêmicos e os agentes da sociedade civil organizada às agendas públicas realmente voltadas ao atendimento das demandas das populações, e não à legitimação do mercantilismo da globalização neoliberal.

Em sua análise, Dias Sobrinho (2005b, p. 172) considera que a educação superior é importante na medida em que "[...] seja um bem público e [...] desenvolva o conhecimento e a formação como bens comuns e direitos de todos [...]" e, também, "[...] que sirva ao desenvolvimento econômico, porém como um instrumento de humanização e não como horizonte último e razão determinante da sociedade." Nessa perspectiva, a autonomia e a solidariedade são valores que devem ser construídos, com o intuito de que o:

[...] aumento da produtividade e o fortalecimento da dimensão material das sociedades não se afastem da produção de maior eqüidade, inclusão e participação social. Não há porque rejeitar os progressos materiais se eles efetivamente vêm fundados na produção de sentidos, na ética da justiça social, das políticas de maior inclusão e da mais ampla participação dos cidadãos na vida pública (DIAS SOBRINHO, 2005b, p. 172).

A universidade, na concepção de Habermas (1993), deve recuperar sua função de ser o lugar em que os processos de aprendizagem devem ser privilegiados. Segundo Habermas (1993, p. 122) "[...] o sistema científico diferenciado não deve desenvolver-se apenas em ligação com a economia, a técnica e a administração, mas antes, por meio da sua tradicional convergência de funções, manter-se enraizado no "mundo da vida." Embora a universidade acompanhe as inovações, não deve deixar de priorizar suas principais funções que estão relacionadas ao desenvolvimento social, cultural e ético.

Habermas (1993, p. 128) afirma que "[...] são as formas comunicativas da argumentação científica que afinal permitem dar coesão e unidade aos processos de 
aprendizagem universitária nas suas diversas funções." Desta forma, o autor defende que todos os indivíduos, em seus mundos da vida, têm competência para aceitar ou rejeitar argumentos, em contextos conflituosos, problemáticos, reflexivos e deliberativos, não sendo função exclusiva das comunidades de eruditos, "[...] reformulando assim aquela idealização iluminista do uso público da razão, e abrindo uma via de articulação entre as universidades, a esfera pública e os mundos da vida." (GONZÁLEZ DE GOMÉZ, 2011, p. 236).

Outra questão importante relacionada à universidade na sociedade contemporânea, especialmente a universidade brasileira, diz respeito à forma de administração. Segundo Bernheim e Chauí (2008, p. 12), a universidade atual passa a ser considerada

[...] organização administrada (no sentido em que Adorno e Horkheimer empregam o conceito de administração capitalista) [...]. Governada mediante contratos de gestão, avaliada com base em indicadores de produtividade e projetada para ser flexível, a universidade é estruturada por estratégias e programas de eficiência organizacional, ou seja, pela particularidade e instabilidade dos meios e objetivos.

É importante esclarecer que a reforma do Estado realizada no governo brasileiro, afeta a universidade no país, principalmente a universidade pública. Segundo Chauí (2003, p. 6) essa reforma,

[...] ao definir os setores que compõem o Estado, designou um desses setores como setor de serviços, não exclusivos do Estado e nele colocou a educação, a saúde e a cultura. Essa localização da educação no setor de serviços não exclusivos do Estado significou: a) que a educação deixou de ser concebida como um direito e passou a ser considerada um serviço; b) que a educação deixou de ser considerada um serviço público e passou a ser considerada um serviço que pode ser privado ou privatizado. [...]. A reforma do Estado definiu a universidade como organização social e não como uma instituição social (grifo nosso). ${ }^{1}$

Neste cenário em que as universidades passam por mudanças que provocam rupturas em seus modelos estabelecidos, as unidades a elas vinculadas também são afetadas pelos impactos dessas transformações. A biblioteca universitária, como

\footnotetext{
${ }_{1}^{1}$ A Lei no 9.637 de 15 de maio de 1998 "Dispõe sobre a qualificação de entidades como organizações sociais, a criação do Programa Nacional de Publicização, a extinção dos órgãos e entidades que menciona e a absorção de suas atividades por organizações sociais, e dá outras providências." (BRASIL, 1998).
} 
instituição partícipe de todo esse processo, precisa ser adequada às exigências do novo contexto, para atender às novas demandas e, assim, fortalecer a parceria com a comunidade acadêmica.

Sobre a importância da biblioteca universitária para a universidade, destaca-se o ponto de vista de González de Gómez (2011, p. 239), ao enfatizar que:

\begin{abstract}
A recomposição virtual de uma esfera pública ampla a partir das plurais esferas públicas situadas hoje em estruturas ainda segmentares da universidade (Escolas, departamentos, redes temáticas de pesquisa) pode ter nos sistemas de Bibliotecas Universitárias um ator privilegiado, enquanto aberto a parcerias e a re-significações de práticas, instrumentos, mediações. Um ponto diferencial seria sua intervenção para promover a articulação das esferas públicas internas das "pequenas sociedades" disciplinares [...] com as esferas públicas e os múltiplos atores da sociedade civil e os públicos anônimos que lutam pela construção da voz; atualização do papel da universidade - aninhadas nas esferas públicas, com seus feixes de funções, unificadas não por uma unidade ideal da ciência nem por uma forma administrativa abstrata, mas pela sua imersão nas heterogêneas e porosas esferas comunicativas dos mundos da vida.
\end{abstract}

Sob essa perspectiva, as bibliotecas universitárias podem ser consideradas parte das expectativas e das possibilidades da construção de espaços comuns do conhecimento, que reúnem as tecnologias de informação e comunicação e as energias "[...] reflexivas e produtivas de seus processos infocomunicacionais, como sua contribuição para tornar permeáveis e interativas as esferas públicas internas dos campos disciplinares e as esferas práticas e instrumentais das complexas sociedades contemporâneas." (GONZÁLEZ DE GÓMEZ, 2011, p. 240).

As bibliotecas universitárias seguem as diretrizes e as políticas de sua universidade mantenedora e, por isso, sua autonomia é limitada. Sua missão é apoiar as atividades de ensino, pesquisa e extensão da universidade, contudo, sua estrutura e serviços, de forma geral, têm características próprias.

Durante muito tempo, essas bibliotecas são reconhecidas como o repositório do conhecimento das universidades, cujo objetivo principal é proporcionar o acesso a esse conhecimento e, assim, transmití-lo às novas gerações. Entretanto, na atualidade, a biblioteca universitária está deixando o seu lugar como principal fonte de busca, em virtude, principalmente, da evolução das tecnologias.

É importante observar, também, que pesquisa realizada no Brasil, no ano de 2012, pela Interactive Advertising Bureau (IAB) em parceria com a empresa de pesquisas de 
mercado comScore, com o objetivo de analisar os hábitos dos internautas brasileiros e identificar a relação destes usuários com a publicidade digital, revela que "[..] 82\% dos brasileiros com acesso a internet consideram a web uma ferramenta indispensável e essencial para a sobrevivência." Além disso, a pesquisa mostra que "[...] a internet é preferencialmente usada pelos jovens, mas que o uso da web é feito por pessoas de todas as idades, classes e regiões, além de ser a atividade preferida para entreter." (FERRER, 2012).

O panorama apresentado mostra mudança nos hábitos e comportamentos de busca por informação. As tecnologias de informação e comunicação influenciam, de forma contundente, a relação usuário - biblioteca - fonte de informação. $O$ ambiente informacional passa a ser, em grande escala, virtual, deixando de ser exclusivamente presencial.

Na opinião de Vergueiro, Castro Filho e Silva (2011, p. 67):

Cada vez mais, o modelo convencional de propriedade dos materiais informativos perde espaço para o modelo de acesso atual. Hoje, as bibliotecas universitárias são instituições híbridas, tanto no sentido de armazenamento do acervo como na prestação dos serviços, em ambos os casos abrangendo elementos físicos e eletrônicos.

Neste cenário, emerge, também, a discussão sobre a "[...] desmaterialização da biblioteca e da obsolescência da ideia de biblioteca como espaço [...]" (AMANTE, 2007, p. 2). Entretanto, em meio ao debate, é importante considerar que as bibliotecas, especialmente as universitárias, constituem-se em ambientes de aprendizagem, onde os usuários estudam, realizam investigações e se encontram. "Esta ideia é tão forte que, em muitos países, a construção de novos edifícios para a biblioteca deixou de ter como prioridade a arrumação física dos materiais e passou a considerar os utilizadores e as atividades por si desenvolvidas." (AMANTE, 2007, p. 3).

As mudanças sociais e econômicas impactam no desenvolvimento e a sustentabilidade das bibliotecas universitárias, e estudos são realizados com o objetivo de identificar tendências e/ou propostas para as mesmas. Em nível nacional pode-se citar o trabalho de Cunha (2010) e em nível internacional, destacam-se as pesquisas desenvolvidas pelo $\mathrm{ACRL}^{2}$ Research, Planning and Review Committee ${ }^{3}$, um componente do Research Coordinating Committee.

${ }^{2}$ A Association of College \& Research Libraries (ACRL) é uma divisão da American Library Association (ALA).

${ }^{3} \mathrm{O}$ comitê é responsável por criar e atualizar uma varredura contínua e dinâmica no ambiente que engloba as tendências nas bibliotecas universitárias, no ensino superior e de forma mais ampla, como, por exemplo, no ambiente econômico, demográfico e político, proporcionando anualmente uma varredura 
A expansão do espaço virtual e o reaproveitamento do espaço físico nas bibliotecas, a ênfase cada vez maior na cooperação e na colaboração entre os bibliotecários, o E-science, a curadoria de dados, a preocupação com a preservação de documentos digitais, com as mudanças na educação superior e com a gestão de pessoas (bibliotecários) são algumas questões também contempladas nos estudos que, juntamente com as anteriores, apontam necessidade de adequação da biblioteca universitária às novas demandas da sociedade contemporânea. Para isso, é fundamental repensar a biblioteca universitária como um todo, extrapolando o conceito de biblioteca tradicional, balizada basicamente na posse da informação, para espaço facilitador da aprendizagem e de socialização, que seja provedor de acesso a múltiplas fontes de informação e, ao mesmo tempo, represente fórum de interação e colaboração entre os usuários, entre esses e os bibliotecários, entre os parceiros da biblioteca e os funcionários da universidade com os bibliotecários.

\section{ADMINISTRAÇÃO DISCURSIVA}

A distorção comunicativa é comum no âmbito das organizações, centradas na lógica competitiva do mercado econômico, em que os indivíduos são considerados instrumentos que podem ser manipulados (VIZEU, 2005).

A cultura organizacional capitalista fomenta a concorrência entre os membros da organização, visando à eficiência e à eficácia. No entanto, a competição de todos contra todos limita a comunicação, impedindo que as informações relevantes fluam livremente por toda a organização. Por sua vez, a “[...] competição gera o ‘segredo do negócio' entre as divisões, de modo que as possibilidades de colaboração entre elas tornam-se cada vez mais exíguas." (GUTIERREZ, 1999, p. xi). Assim, a comunicação interna nas organizações é estruturada em fluxos orientados para o sucesso e, dessa forma, os participantes dos processos internos - os membros da organização - são geridos para agir de acordo com esses interesses, o que acarreta a perda da autonomia para agir, para falar e para facilitar a circulação das falas (LIMA; CARVALHO; LIMA, 2010).

ambiental rápida. Além disso, o comitê tem como responsabilidade identificar "as 10 maiores tendências" da ACRL e divulgá-las de 2 em 2 anos. Para identificá-las, os membros do comitê fazem revisão de literatura, participam de conferências e entram em contato com especialistas familiarizados com as tendências atuais relacionadas à educação superior (ASSOCIATION OF COLLEGE AND RESEARCH LIBRARIES, 2012). 
A linguagem, nesse caso, é utilizada apenas como instrumento nas organizações, com o objetivo de auxiliar o alcance dos objetivos. "O esforço focado na rentabilidade resulta em redução dos participantes dos processos produtivos a condição de trabalhadores silenciosos." (LIMA; CARVALHO; LIMA, 2010, p. 14). Entretanto, a linguagem é inerente ao ser humano e o seu uso nas organizações, como expressão, representação e integração ${ }^{4}$, não apenas como instrumento, possibilita a comunicação entre os indivíduos, o que é fundamental para que se produzam e compartilhem valores e conhecimentos. Nesse sentido, o discurso nas organizações amplia as perspectivas de representação de seus interesses, "[...] politizando suas decisões e possibilitando a racionalização mediadora discursiva." (LIMA; CARVALHO; LIMA, 2010, p. 15). Assim, o discurso

[...] tem papel ativo na transformação das organizações, valorizando e viabilizando expressão e comunicação entre os que participam dos processos produtivos. A ampliação da expressão das perspectivas e a viabilidade da comunicação que vão proporcionar a aprendizagem a partir dos próprios processos produtivos (LIMA; CARVALHO; LIMA, 2010, p. 15).

A Teoria do Agir Comunicativo e a Ética do Discurso, de Jürgen Habermas, podem contribuir para o desenvolvimento de abordagem não funcionalista da Administração, baseada na discussão argumentativa como forma de mediar situações de conflito de poder e fixar ações comuns.

Segundo Habermas (1989), a discussão prática ocorre quando o modo de agir carece de fundamentação de natureza coletiva e as pessoas precisam chegar a uma decisão comum sobre suas ações, e têm que tentar convencer-se mutuamente de que é interessante para cada um que todos ajam assim. Neste processo, cada um indica ao outro as razões por que ele pode querer que um modo de ação seja tornado socialmente obrigatório. Cada pessoa tem de se convencer de que a norma proposta é igualmente boa para todos. A discussão pode criar argumentos que legitimem a decisão de orientações para a ação coletiva e acordos práticos.

\footnotetext{
${ }^{4}$ Segundo González de Goméz (2009, p. 116), "A potência da linguagem sobre a qual se sustenta a racionalidade comunicativa é exercida em três direções: como representação, pela remissiva do enunciado a um domínio de referência; como comunicação, enquanto construção em comum de significados e instauração do compromisso pragmático entre os participantes da ação comunicativa; como expressão da subjetividade, por colocar o ator social frente aos outros, parceiros, públicos ou oponentes, dando ocasião à atitude reflexiva e à formação de identidades, que são condições da autonomia e responsabilidade de sujeitos imputáveis."
} 
$\mathrm{Na}$ administração discursiva, denominação adotada por Lima, Carvalho e Lima (2010), podem ser construídos valores e normas comuns. Esta forma de administração, que valoriza a relação intersubjetiva entre todos os indivíduos e de forma igualitária, prioriza a tomada de decisão coletiva e consensual, sem qualquer tipo de coação, possibilitando a aprendizagem, a melhoria de processos e a inovação. Segundo Lima, Carvalho e Lima (2010, p. 1),

A inclusão dos participantes aumenta a complexidade da organização, que resulta em colaboração com autonomia e vincula as finalidades da organização ao mundo da vida, tornando-a capaz de produzir riqueza e bem-estar socialmente distribuídos.

Vizeu (2005, p. 15) destaca que, em função da centralidade da interação linguística na práxis social, o agir comunicativo representa:

[...] construto que integra múltiplas visões de mundo e de indivíduo, e essa multiplicidade é relevante para a compreensão do fenômeno organizacional. Permite que se verifiquem contradições nas relações interpessoais nem sempre enfocadas pelos estudos organizacionais, já que a idéia de distorção comunicativa, antes de ser um mero problema de comunicação organizacional, reflete a dificuldade de reconhecimento do outro enquanto sujeito competente, enquanto membro integrante de uma mesma comunidade cultural.

Assim, a administração discursiva, ancorada nas teorias de Habermas, pode ser considerada forma de administração viável na sociedade contemporânea, principalmente porque tem "[...] o potencial de enfrentar os problemas decorrentes da redução da dinâmica da comunicação nos sistemas, com a inclusão das perspectivas dos seus participantes." (LIMA; CARVALHO, 2011, p. 51). Na administração discursiva todos os membros da organização participam dos seus processos, não apenas executando tarefas, mas compartilhando informações e pensando os problemas de forma crítica, buscando soluções e acordos práticos. Além disso, esta forma de administração influencia as relações do sistema com o seu entorno, na medida em que favorece a interação, baseada no respeito e no diálogo, com os atores externos (LIMA; CARVALHO, 2011).

Alguns elementos ${ }^{5}$ relacionados às teorias de Habermas são fundamentais para que a administração seja discursiva, ou se consiga implantar uma gestão comunicativa ${ }^{6}$, conforme apresentado na figura 1. Cada elemento pode ser entendido como:

\footnotetext{
${ }^{5}$ Baseado em Guiterrez (1999).
} 
Figura 1 - Elementos fundamentais para uma administração discursiva

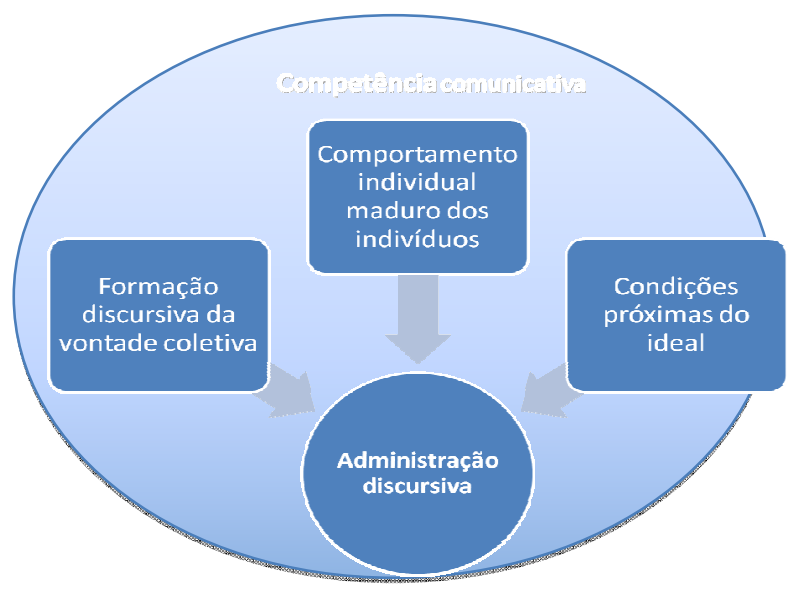

Fonte: Baseado em Gutierrez, 1999.

a) Formação discursiva da vontade coletiva

Segundo Habermas (1990, p. 74), as interações comunicativas, através dos atos de fala realizados sem reserva, coloca as orientações da ação e os processos de fala, adaptados conforme $o$ ator, sob os limites estruturais de uma linguagem compartilhada intersubjetivamente. Essas limitações impõem a seguinte mudança: "[...] os atores têm de abandonar o enfoque objetivador de um agente orientado pelo sucesso [...] e assumir o enfoque performático de um falante, o qual procura entender-se com uma segunda pessoa sobre algo no mundo."

Procura-se, por meio da formação discursiva da vontade coletiva, o "[...] desarmamento das posturas estratégicas em benefício do grupo, a partir de uma situação onde todos os participantes achem satisfeitas suas exigências de validade para o plano comum de ação." (GUTIERREZ, 1999, p. 36).

b) Comportamento individual maduro dos indivíduos

Este tipo de comportamento, como ressalta Gutierrez (1999), compreende desde as "[...] normas de educação até a ausência de desvios patológicos que possam impedir a

\footnotetext{
${ }^{6}$ A Gestão comunicativa, denominação adotada por Gutierrez (1999), significa "[...] implantar na multiempresa um tipo de gestão em que passariam a prevalecer valores do mundo da vida, ou seja, em que as pessoas seriam convencidas a deixar de integrar coligações rivais e em vez disso exerceriam a ação comunicativa para negociar um consenso entre todos. Este consenso deveria substituir os objetivos particulares e exclusivos pelo objetivo comum de maximizar o desempenho da multiempresa como um todo." (GUTIERREZ, 1999, p. xi).
} 
percepção do sentido geral de uma discussão, ou a revisão pessoal de comportamentos e conceitos quando confrontados com argumentos distintos."

Habermas (1989, p. 154) observa que o desenvolvimento moral significa:

[...] que a pessoa em crescimento transforma e diferencia de tal maneira as estruturas cognitivas já disponíveis em cada caso que ela consegue resolver melhor do que anteriormente a mesma espécie de problemas, a saber, a solução consensual de conflitos de ação moralmente relevantes. Ao fazer isso, a pessoa em crescimento compreende o seu próprio desenvolvimento moral como um processo de aprendizagem. [...] As estruturas cognitivas que subjazem à faculdade de julgar moral não devem ser explicadas nem primariamente por influências do mundo ambiente, nem por programas inatos e processos de maturação, mas, sim, como o resultado de uma reorganização criativa de um inventário cognitivo préexistente e que se viu sobrecarregado por problemas que reaparecem insistentemente.

c) Condições próximas do ideal

Essas são condições básicas que viabilizam as interações comunicativas, como liberdade, autonomia, segurança, acesso às informações, diálogo e compromisso entre todos os indivíduos (GUTIERREZ, 1999).

Habermas (1989, p. 111) observa que, no discurso argumentativo, "[...] mostram-se estruturas de uma situação de fala que está particularmente imunizada contra a repressão e a desigualdade: ela apresenta-se como uma forma de comunicação suficientemente aproximada de condições ideais." O autor enfatiza, também, que os participantes de uma argumentação:

[...] não podem se esquivar à pressuposição de que a estrutura de sua comunicação, em razão de características a se descreverem formalmente, exclui toda coerção atuando do exterior sobre o processo de entendimento mútuo ou precedendo dele próprio, com exceção da coerção do argumento melhor, e que ela assim neutraliza todos os motivos, com exceção do motivo da busca cooperativa da verdade (HABERMAS, 1989, p. 111).

\section{d) Competência comunicativa}

Cabe enfatizar a importância da competência comunicativa em todo esse processo. A utilização da linguagem para fins de entendimento está relacionada a um saber intuitivo que os indivíduos socializados possuem e que se revela como uma "[...] competência comunicativa adquirida pela inserção no mundo da vida e que os indivíduos utilizam na ação comunicativa." (BOUFLEUER, 2001, p. 36). Ainda segundo o autor, 
A competência comunicativa consiste no domínio não-reflexivo (préteórico) de certas pressuposições que acompanham o entendimento lingüístico. Tais pressuposições têm caráter similar ao das regras gramaticais, que o indivíduo utiliza ao falar e que nem por isso lhe são conscientes. Portanto, da mesma forma como o indivíduo que fala é capaz de utilizar corretamente as regras gramaticais, mesmo sem dominá-las reflexivamente, assim também os sujeitos capazes de linguagem e de ação fazem uso de certas pressuposições pragmáticas ao utilizarem a linguagem voltada ao entendimento. Esse saber pré-teórico, que serve ao entendimento linguístico, pode ser reconstruído racionalmente numa perspectiva universalista [...] (HABERMAS, 1989 apud BOUFLEUER, 2001, p. 36).

É importante acrescentar que o discurso pode ser entendido como esfera da aprendizagem, uma vez que "[...] o aprendizado é socialmente determinado por interações subjetivas e intersubjetivas entre os atores no processo de interação mediado pela linguagem em contextos específicos." (LIMA; CARVALHO; LIMA, 2010, p. 15). Assim, as organizações que fomentam a comunicação e a cooperação entre os indivíduos favorecem a aprendizagem, sendo caracterizadas como "[...] sistema cognitivo capaz de sustentar processos de aprendizagem, isto é, as organizações que discutem são organizações capazes de aprender." (LIMA; CARVALHO; LIMA, 2010, p. 15).

Nesse sentido, a administração discursiva pode ser considerada uma forma de administração possível e coerente com as demandas da sociedade contemporânea, possibilitando aos membros da organização o estabelecimento de relações gratificantes e duradouras, o alcance de níveis significativos de autorrealização e aprendizado e o embasamento de suas ações, a partir de uma racionalidade comunicativa, e, por outro lado, proporcionando às organizações o alcance de níveis satisfatórios de desempenho.

\section{PERSPECTIVAS DE ADMINISTRAÇÃO DISCURSIVA NAS BIBLIOTECAS UNIVERSITÁRIAS}

As organizações mudam constantemente, seja por influência externa, seja por necessidades internas - essas em menor intensidade - e os reflexos dessas transformações repercutem em toda a sua estrutura e, principalmente, na cultura organizacional. Nesse sentido, é fundamental que sejam administradas de forma cautelosa, possibilitando o atendimento das demandas internas, assim como auxiliando na adaptação aos novos contextos ambientais. 
A biblioteca universitária também se enquadra nesse contexto. Deve ser administrada de forma que acompanhe as mudanças e cumpra sua missão e seus objetivos com excelência e, assim, possa atender às suas próprias necessidades e às de seus usuários, além de auxiliar a universidade a exercer plenamente suas funções social e formativa. A trajetória das bibliotecas universitárias é marcada pela utilização de diversas formas de administração que, de alguma maneira, têm relação com o tipo de administração adotado nas universidades, em virtude do vínculo existente entre a biblioteca e a instituição na qual se insere.

A pesquisa realizada mostra as formas de administração utilizadas nas bibliotecas universitárias brasileiras, na sociedade contemporânea, divulgadas no Seminário Nacional de Bibliotecas Universitárias (SNBU), apontando algumas tendências relacionadas à administração dessas bibliotecas. O Seminário tem importância reconhecida, uma vez que se constitui em fórum de discussão, troca de ideias e estabelecimento de parcerias, proporcionando aos profissionais que atuam nas bibliotecas universitárias o acesso aos estudos e às pesquisas desenvolvidos na área, além do importante contato com profissionais de bibliotecas congêneres e de empresas e instituições que participam do evento.

Assim, a pesquisa compreende os anos de 2004, 2008 e 2012, período que abrange anos intercalados, escolhidos de forma aleatória. Esse tipo de escolha também é válido para a quantidade de eventos arrolados. Do total de 189 comunicações orais em 2004, 178 em 2008 e 198 em 2012, são selecionadas para amostra aquelas que contêm os termos "gestão" ou "administração" na palavra-chave e no título. No primeiro campo, são encontradas 82 comunicações e, no segundo, 56. Em seguida, é realizado o cotejamento dos dados, o que resulta em 100 comunicações orais. A classificação dos dados selecionados na amostra é realizada por meio de categorias temáticas, definidas com base nos assuntos identificados no título, na palavra-chave e no resumo de cada comunicação oral. Cada uma das categorias é conceituada, conforme apresentado no quadro 2. As categorias temáticas representam as formas de administração que compreendem processos, estratégias, políticas, práticas, metodologias, modos de gestão e estilos relacionados à administração de uma organização. 
Quadro 2 - Categorias temáticas utilizadas para classificar as comunicações orais

\begin{tabular}{|c|c|}
\hline $\begin{array}{l}\text { Categorias } \\
\text { temáticas }\end{array}$ & Conceituação \\
\hline $\begin{array}{l}\text { Administração } \\
\text { estratégica }\end{array}$ & $\begin{array}{l}\text { "[...] processo amplo que permite à organização procurar atingir o seu propósito ao } \\
\text { longo do tempo. Esse processo abrange a visão, a formulação e a implementação, } \\
\text { bem como o feedback contínuo e a avaliação dos resultados, tendo em vista } \\
\text { orientar e empreender as ações organizacionais de natureza estratégica, tática e } \\
\text { operacional." (ALBUQUERQUE, 2002, p. } 40 \text { ). }\end{array}$ \\
\hline $\begin{array}{l}\text { Administração } \\
\text { participativa }\end{array}$ & $\begin{array}{l}\text { "[...] filosofia ou política de administração de pessoas que valoriza sua capacidade } \\
\text { de tomar decisões e resolver problemas. [...] A administração participativa aprimora } \\
\text { a satisfação e a motivação no trabalho. [...] A administração participativa contribui } \\
\text { para o melhor desempenho e a competitividade das organizações." (MAXIMIANO, } \\
\text { 1995, p. 19-20). }\end{array}$ \\
\hline $\begin{array}{l}\text { Gestão } \\
\text { ambiental }\end{array}$ & $\begin{array}{l}\text { "Condução, direção, proteção da biodiversidade, controle do uso de recursos } \\
\text { naturais, através de determinados instrumentos, que incluem regulamentos e } \\
\text { normatização, investimentos públicos e financiamentos, requisitos } \\
\text { interinstitucionais e jurídicos. Este conceito tem evoluído para uma perspectiva de } \\
\text { gestão compartilhada pelos diferentes agentes envolvidos e articulados em seus } \\
\text { diferentes papéis, a partir da perspectiva de que a responsabilidade pela } \\
\text { conservação ambiental é de toda a sociedade e não apenas do governo, e } \\
\text { baseada na busca de uma postura pró-ativa de todos os atores envolvidos." } \\
\text { (FULGENCIO, 2007, p. 309). }\end{array}$ \\
\hline $\begin{array}{l}\text { Gestão da } \\
\text { informação }\end{array}$ & $\begin{array}{l}\text { "[...] conjunto de estratégias que visa identificar as necessidades informacionais, } \\
\text { mapear os fluxos formais de informação nos diferentes ambientes da organização, } \\
\text { assim como sua coleta, filtragem, análise, organização, armazenagem e } \\
\text { disseminação, objetivando apoiar o desenvolvimento das atividades cotidianas e a } \\
\text { tomada de decisão no ambiente corporativo [...]" (VALENTIM, 2004). }\end{array}$ \\
\hline $\begin{array}{l}\text { Gestão da } \\
\text { mudança }\end{array}$ & $\begin{array}{l}\text { "Processo de reinvenção e/ou reestruturação continuadas da cultura, estratégia e } \\
\text { estrutura de uma organização." (FULGENCIO, 2007, p. 309). }\end{array}$ \\
\hline $\begin{array}{l}\text { Gestão da } \\
\text { qualidade total }\end{array}$ & $\begin{array}{l}\text { "Modo de gestão de uma organização, centrada na qualidade, baseado na } \\
\text { participação de todos os seus membros, visando ao sucesso de longo prazo, } \\
\text { através da satisfação do cliente e dos benefícios para os membros da organização } \\
\text { e para a sociedade." (FULGENCIO, } 2007, \text { p. } 309 \text { ). }\end{array}$ \\
\hline $\begin{array}{l}\text { Gestão de } \\
\text { pessoas }\end{array}$ & $\begin{array}{l}\text { "[...] refere-se às políticas e práticas necessárias para administrar o trabalho das } \\
\text { pessoas, tais como: [...] Agregar talentos à organização [...] Integrar e orientar } \\
\text { talentos em uma cultura participativa, acolhedora e empreendedora [...] Modelar o } \\
\text { trabalho seja individual ou em equipe de maneira à torná-lo significativo, agradável } \\
\text { e motivador [...] Recompensar os talentos pelo excelente desempenho e pelo } \\
\text { alcance de resultados como reforço positivo [...] Avaliar o desempenho humano e } \\
\text { melhorá-lo continuamente [...] Comunicar, transmitir conhecimento e proporcionar } \\
\text { retroação intensiva [...] Treinar e desenvolver talentos para criar uma organização } \\
\text { de aprendizagem [...] Proporcionar excelentes condições de trabalho e melhorar a } \\
\text { qualidade de vida no trabalho [...] Manter excelentes relações com talentos, } \\
\text { sindicatos e comunidade em geral [...] Aumentar a competitividade dos talentos } \\
\text { para incrementar o capital humano da organização e, conseqüentemente, o capital } \\
\text { intelectual [...] Incentivar o desenvolvimento organizacional." (CHIAVENATO, 2008, } \\
\text { p. 15). }\end{array}$ \\
\hline $\begin{array}{l}\text { Gestão de } \\
\text { processos }\end{array}$ & $\begin{array}{l}\text { "Um conjunto articulado de tarefas permanentes para projetar e promover o } \\
\text { funcionamento e o aprendizado sobre os processos. Essas tarefas podem ser } \\
\text { agrupadas em: [...] desenhar processos com o objetivo de definir ou redefinir como } \\
\text { os processos devem ser projetados para serem melhorados e implantados. [...] } \\
\text { gerir os processos no dia-a-dia com o objetivo de assegurar a efetiva } \\
\text { implementação dos processos e a realização de alocação de recursos para sua } \\
\text { execução, bem como a realização de mudanças e adaptações de curto prazo. [...] } \\
\text { promover a evolução dos processos e o constante aprendizado com o objetivo de } \\
\text { registrar o conhecimento gerado sobre os processos e construir uma base para que } \\
\text { seja criado conhecimento para sustentar a evolução dos processos." (PAIM et al., } \\
2009, \text { p. 139). }\end{array}$ \\
\hline & "[...] aplicação de conhecimento, habilidades, ferramentas e técnicas às atividades \\
\hline
\end{tabular}




\begin{tabular}{|c|l|}
\hline $\begin{array}{c}\text { Gestão de } \\
\text { projetos }\end{array}$ & $\begin{array}{l}\text { do projeto a fim de atender aos seus requisitos. O gerenciamento de projetos é } \\
\text { realizado através da aplicação e da integração dos seguintes processos: [...] } \\
\text { iniciação, planejamento, execução, monitoramento e controle, e encerramento." } \\
\text { (PROJECT MANAGEMENT INSTITUTE, 2004, p. 8). }\end{array}$ \\
\hline $\begin{array}{c}\text { Gestão do } \\
\text { conhecimento }\end{array}$ & $\begin{array}{l}\text { "[...] conjunto de estratégias para criar, adquirir, compartilhar e utilizar ativos de } \\
\text { conhecimento, bem como estabelecer fluxos que garantam a informação } \\
\text { necessária no tempo e formato adequados, a fim de auxiliar na geração de idéias, } \\
\text { solução de problemas e tomada de decisão [...]" (VALENTIM, 2004). }\end{array}$ \\
\hline Marketing & $\begin{array}{l}\text { "[...] processo de planejar e executar a concepção, a determinação de preço } \\
\text { (pricing), a promoção e a distribuição de idéias, bens e serviços para criar } \\
\text { negociações que satisfaçam metas individuais e organizacionais." (KOTLER, 2000, } \\
\text { p. 30). }\end{array}$ \\
\hline Outros & Aborda formas de administração que não se enquadram nas categorias anteriores. \\
\hline
\end{tabular}

Fonte: Autores.

O gráfico 1 mostra, em termos percentuais, as comunicações orais classificadas por categoria temática, representando as formas de administração utilizadas nas bibliotecas universitárias brasileiras.

Gráfico 1 - Comunicações orais por categoria temática

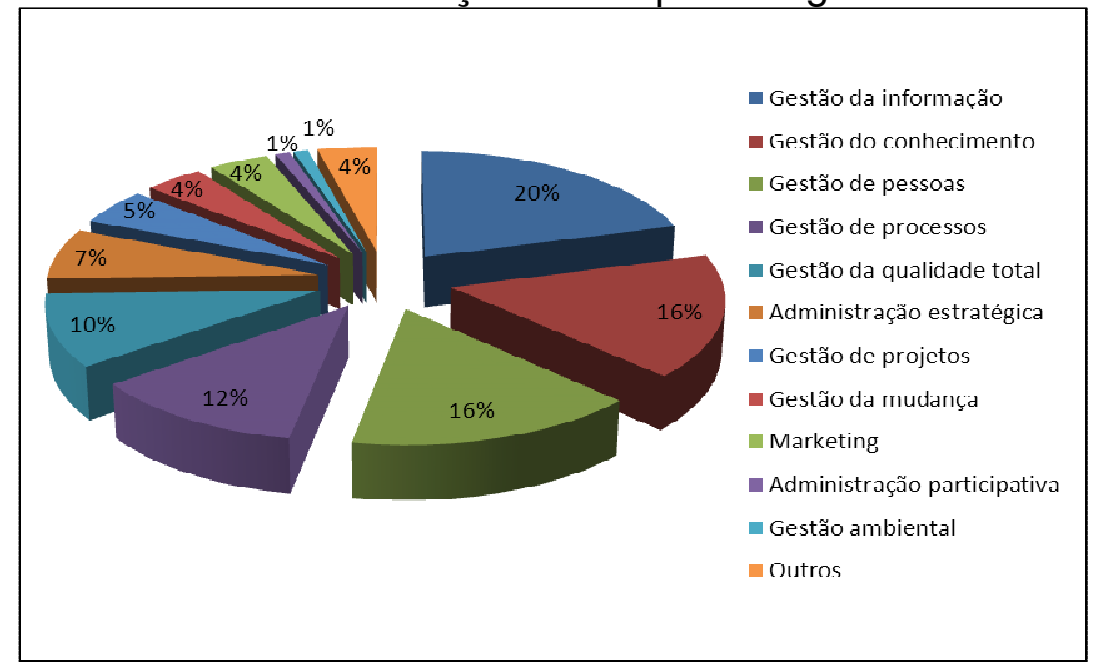

Fonte: Autores.

As diversas formas de administração utilizadas nas bibliotecas universitárias brasileiras, identificadas na pesquisa, mostram a busca por caminhos e formas de atuação, principalmente com base nas abordagens contemporâneas da Administração, 0 que indica o estreito vínculo entre essa área e a Biblioteconomia.

O resultado da pesquisa revela que os pressupostos da administração discursiva não são identificados no universo analisado e sugere, também, a predominância de racionalidade instrumental nessas bibliotecas, tipo de racionalidade que favorece o agir estratégico e a distorção comunicativa, o que reduz as relações entre os membros da organização à dimensão objetiva. Entretanto, as bibliotecas universitárias podem ser 
pensadas a partir de uma dinâmica de interações e de agir comunicativo, o que abre caminho para interpretação menos ligada à racionalidade instrumental e mais focada em uma racionalidade comunicativa.

Dessa forma, a administração discursiva pode ser considerada uma alternativa interessante, uma vez que possibilita a interação entre as pessoas e a reflexão coletiva, e, além disso, amplia a forma de perceber e entender os problemas práticos e de buscar soluções.

Um aspecto fundamental dessa abordagem é a busca da integração, da possibilidade de um projeto solidário, que deve ser compreendido como desafio gerencial permanente. Para isso, os fluxos de comunicação devem ser ampliados e deve ser estimulado o diálogo, visando à construção de projetos que possam ser assumidos por todos como compromissos. Nessa perspectiva, é imprescindível a descentralização do poder, a delegação permanente e a administração criativa e voltada à aprendizagem. É fundamental que o gestor deixe de ser apenas um observador, para atuar como participante na dinâmica comunicacional, e que a tomada de decisão aconteça de forma coletiva e consensual.

A utilização desta forma de administração implica tanto mudanças organizacionais como também pessoais, constituindo-se em processo gradativo de aprendizado que deve envolver toda a organização.

Nas bibliotecas universitárias, como em qualquer outra organização, mudança envolve planejamento, que, por sua vez, deve ser participativo, valorizando o diálogo e a transparência do processo como um todo. É o momento de se entender a situação atual e decidir-se para onde ir e de que forma, levando-se em consideração diversos fatores, como as características da biblioteca e da universidade a que está vinculada, as necessidades, expectativas e desejos do público a que atende, as demandas e os desafios impostos pela sociedade contemporânea.

É condição sine qua non que os membros da organização conheçam e aceitem a proposta da administração discursiva. No caso da biblioteca universitária, devem ser consultados bibliotecários, técnicos e auxiliares, como também estagiários e profissionais de outras áreas que atuam na biblioteca. Além disso, os gestores e/ou representantes da universidade também devem ser consultados. $O$ apoio da universidade é fundamental, pois garante, em nível organizacional, a seriedade e a duração da proposta. O processo de planejamento da mudança deve ser conduzido de forma coesa e harmônica e envolver 
os membros da biblioteca e os gestores e/ou representantes da universidade. Devem ser realizadas reuniões, em que a proposta é discutida e são realizados os esclarecimentos necessários. Após o aceite de todos, devem ser estabelecidos os direcionamentos para a concretização da proposta. Algumas ações devem ser empreendidas ${ }^{7}$, para que a administração discursiva seja utilizada nas bibliotecas universitárias em sua plenitude. Dentre elas, destacam-se:

a) Ajustar a prática interna da biblioteca ao novo contexto, sempre de forma transparente e colaborativa. Isso inclui, por exemplo, a missão, os objetivos, as metas, as políticas, as atividades, sejam rotineiras ou não, os fluxos de trabalho e os procedimentos;

b) investir na consolidação de um ambiente de segurança e liberdade, que incentive formas cooperativas e inovadoras de relacionamento interpessoal;

c) procurar minimizar o ambiente estratégico, favorecendo a substituição das relações estratégicas pelas relações originais do mundo da vida;

d) analisar a cultura organizacional, enquanto elemento de viabilidade da mudança, visando ao estabelecimento de metodologia para o seu acompanhamento;

e) incentivar a harmonia entre a vida pessoal dos membros da biblioteca e a cultura organizacional;

f) viabilizar o acesso às informações;

g) incentivar o aperfeiçoamento individual e o desenvolvimento da competência comunicativa;

h) estimular o desenvolvimento de habilidades de liderança, que visem à capacidade de mediação nas relações interpessoais;

i) ampliar os fluxos de comunicação, dentro e fora do ambiente da biblioteca;

\footnotetext{
${ }^{7}$ As ações foram elaboradas com base em Gutierrez (1999), em Lima, Lima e Moreira (2010), em Lima,
} Carvalho e Lima (2010) e Lima e Carvalho (2011). 
j) estimular a participação coletiva, em igualdade de condições, contribuindo para a formação discursiva da vontade coletiva. É fundamental incentivar as pessoas a discutirem, sem medo de represálias, superando a timidez e o receio à exposição;

k) dispor de instrumento que viabilize as relações intersubjetivas, possibilitando que as questões problematizadas sejam discutidas, visando à obtenção de consenso.

Em relação a esse último item, é importante esclarecer que o instrumento em questão pode ser o que Vizeu (2009) chama de "espaços de fala legítimos", espaços que favorecem a interação e o diálogo livremente. Segundo o autor, "No âmbito das organizações, a superação da distorção comunicativa tem sido vislumbrada especialmente pelo estabelecimento dos espaços de fala legítimos e pelo reconhecimento recíproco do outro enquanto um membro da comunidade de fala." (VIZEU, 2009, p. 12).

Webler e Tuler (2000 apud VIZEU, 2009, p. 12) apontam alguns critérios para que os processos de decisão coletiva possam se constituir em espaços de fala legítimos, com base nos critérios de validade da ação comunicativa. São eles:

a. acesso ao processo de decisão, que não somente diz respeito a [sic] presença física do participante no debate, mas também a [sic] possibilidade de falar e ser ouvido;

b. poder para influenciar o processo e seus resultados, tendo em vista que, a competência discursiva somente pode ser considerada como autêntica se ela puder realmente ser efetivada em termos de resultados;

c. interação construtiva facilitada por meio de estruturas adequadas, correspondendo aos aspectos estruturais do debate [...];

d. interação construtiva facilitada por meio de comportamento pessoal, significando a postura pessoal que facilita a confiança e a crítica construtiva, como, por exemplo, a tolerância e a paciência;

e. acesso à informação, tendo em vista que em relação a certas questões somente alguns têm acesso direto a informações e/ou conhecimento especializados;

f. análise adequada da informação, de maneira que esta não seja tendenciosa ou parcial (o que envolve, quando necessário, um 
processo de tradução ou interpretação isento de interesses particulares);

g. habilitação de condições necessárias para processos futuros, de maneira que sejam aproveitadas em outras oportunidades as deliberações que possam ser utilizadas sem nenhum comprometimento, de maneira a não empreender novos processos de discussão e negociação.

Pode-se pensar a Comissão de Biblioteca, existente em muitas bibliotecas universitárias, como um possível "espaço de fala legítimo". Conforme destaca Miranda (1978, p. 6), a Comissão tem como objetivo principal "[...] orientar o Diretor da Biblioteca nas suas decisões quanto a seleção de material bibliográfico, distribuição do orçamento de aquisição, etc.". Entretanto, para que a Comissão de Biblioteca seja utilizada no sentido proposto, seus objetivos, sua estrutura e suas atividades devem ser adequados aos pressupostos da administração discursiva. Nesse sentido, a referida Comissão deve, por exemplo, possibilitar a todos os membros da biblioteca e a todos os demais atores que, de alguma forma, estejam relacionados a ela, a oportunidade de expressar sentimentos, desejos, expectativas, fazer questionamentos, refutar pretensões de validade, sem qualquer tipo de coação, com o objetivo de alcançar o consenso e, assim, auxiliar o desenvolvimento da biblioteca como um todo.

Outros "espaços de fala legítimos" podem ser instituídos nas bibliotecas universitárias, desde que estejam em consonância com os pressupostos da administração discursiva. Cabe ressaltar, também, que esses espaços não precisam, necessariamente, ter uma dimensão física, ou seja, podem ser virtuais, desde que prevaleçam as práticas discursivas.

Uma questão importante, que deve ser levada em consideração na administração discursiva, diz respeito à colaboração, não apenas interna, entre todos os membros da organização, mas também externa. Segundo Carvalho (2009, p. 109),

A colaboração interna e externa facilita não apenas o compartilhamento de informações e conhecimentos, mas também resulta deles. A colaboração viabiliza diálogos, e os diálogos viabilizam colaboração. As organizações não inovam sozinhas, mas sobre informações e conhecimentos acumulados dentro e fora delas. 
Nesse sentido, a colaboração entre todos os membros da biblioteca e também entre esses e os funcionários das demais unidades que compõem a universidade deve ser estimulada, como também com usuários, fornecedores e parceiros em geral, tendo em vista que a colaboração é condição para a melhoria dos processos e para a inovação. Como a tendência é cada vez mais as bibliotecas se tornarem espaço facilitador da aprendizagem e de socialização, em vez de apenas depósito de coleções, propiciando o acesso a múltiplas fontes de informação e também o encontro, a interação e a colaboração entre os usuários, é fundamental que a forma de administração utilizada na biblioteca reflita isso, o que, certamente, agrega valor a essa organização.

\section{CONSIDERAÇÕES FINAIS}

A emergência da sociedade da informação representa quebra de paradigmas em várias dimensões, seja no contexto social e econômico, seja no político e no cultural. A rápida evolução tecnológica, associada a essas mudanças, afeta todos os segmentos da sociedade, inclusive o educacional. Nesse cenário, a universidade sofre pressões para se adequar às demandas da atualidade, o que implica mudanças que provocam rupturas em seus modelos estabelecidos, afetando as unidades a ela vinculadas.

No bojo dessas mudanças, a biblioteca universitária precisa ser repensada e adequada às novas demandas da sociedade contemporânea. Isso envolve envidar esforços para lidar com questões internas e externas que, direta ou indiretamente, impactam essas organizações. A forma de administração adotada na biblioteca deve viabilizar a adaptação às mudanças, priorizando a interação entre as pessoas e a colaboração no ambiente de trabalho, o que favorece o processo como um todo. A comunicação é considerada a palavra de ordem da sociedade contemporânea.

Nesse sentido, a comunicação nas organizações deve ser pensada, principalmente, como forma de construção do entendimento, quanto a resultados e meios para obtê-los. O agir comunicativo e o discurso têm papel fundamental nas organizações, uma vez que valorizam e viabilizam a comunicação entre os que participam dos processos produtivos onde todos definem, de forma cooperativa, seus planos de ação, no horizonte de um mundo da vida compartilhado, tendo por base interpretações comuns da situação. 
A administração discursiva constitui-se em alternativa possível e interessante, coerente com as demandas da sociedade contemporânea e que pode contribuir para 0 desenvolvimento das pessoas, a racionalização dos processos organizacionais, a aprendizagem e a inovação. É uma forma de administração que pode coexistir com outras, desde que os seus pressupostos sejam respeitados. As vantagens da administração discursiva nas bibliotecas universitárias são inúmeras, a saber: possibilita a interação e a colaboração entre as pessoas; viabiliza o diálogo, a autonomia e a liberdade; assegura o compromisso de todos com as decisões e com as escolhas adotadas; democratiza o processo de administração da biblioteca; promove o desenvolvimento, proporcionando melhores resultados para a biblioteca, e, por conseguinte, para a universidade, propiciando o bem-estar pessoal e 0 aprendizado contínuo de seus membros.

\section{REFERÊNCIAS}

ALBUQUERQUE, Lindolfo Galvão. A gestão estratégica de pessoas. In: FLEURY, Maria Tereza Leme (Org.). As pessoas na organização. São Paulo: Gente, 2002. p. 35-50.

AMANTE, Maria João. Bibliotecas universitárias: semear hoje para colher amanhã. In: CONGRESSO NACIONAL DE BIBLIOTECÁRIOS, ARQUIVISTAS E DOCUMENTALISTAS, 9., 2007, Açores. Informação para a cidadania, o desenvolvimento e a inovação: actas. Lisboa: BAD, 2007.

ASSOCIATION OF COLLEGE AND RESEARCH LIBRARIES. Research, planning and review committee. 2012 top ten trends in academic libraries: a review of the trends and issues affecting academic libraries in higher education. College \& Research Libraries News, Chicago, p. 311-320, Jun. 2012.

BARAÑANO, Ana María. Gestão da inovação tecnológica: estudo de cinco PMEs portuguesas. Revista Brasileira de Inovação, Campinas, v. 4, n. 1, p. 57-96, jan./jun. 2005.

BERNHEIM, Carlos Tünnerman; CHAUI, Marilena Souza. Desafios da universidade na sociedade do conhecimento. Brasília: Unesco, 2008.

BOUFLEUER, José Pedro. Pedagogia da ação comunicativa: uma leitura de Habermas. 3. ed. ljuí: Ed. UNIJUÍ, 2001. 
BRASIL. Lei n 9.637, de 15 de maio de 1998. Dispõe sobre a qualificação de entidades como organizações sociais, a criação do Programa Nacional de Publicização, a extinção dos órgãos e entidades que menciona e a absorção de suas atividades por organizações sociais, e dá outras providências. Disponível em: <http://www.planalto.gov.br/ccivil_03/leis//9637.htm>. Acesso em: 1 fev. 2012.

CARVALHO, Lidiane dos Santos. Informação, comunicação e inovação. 2009. 134 f. Dissertação (Mestrado em Ciências da Informação) - Universidade Federal de Santa Catarina, Florianópolis, 2009.

CHAUÍ, Marilena de Souza. A universidade pública sob nova perspectiva. Revista Brasileira de Educação. Rio de Janeiro, n. 24, p. 5-15, set./dez. 2003. Disponível em: <http://www.scielo.br/pdf/rbedu/n24/n24a02.pdf>. Acesso em: 1 out. 2012.

CHIAVENATO, Idalberto. Gestão de pessoas: o novo papel dos recursos humanos nas organizações. 3. ed. Rio de Janeiro: Elsevier, 2008.

CUNHA, Murilo Bastos. A biblioteca universitária na encruzilhada. DataGramaZero Revista de Ciência da Informação, Rio de Janeiro, v. 11, n. 6, dez. 2010. Disponível em: <www.dgz.org.br/dez10/Art_07.htm>. Acesso em: 1 fev. 2012.

DIAS SOBRINHO, José. Dilemas da educação superior no mundo globalizado: sociedade do conhecimento ou economia do conhecimento? São Paulo: Casa do Psicólogo, 2005a.

Educação superior, globalização e democratização: qual universidade? Revista Brasileira de Educação, Rio de Janeiro, n. 28, jan./abr. 2005b.

FERRER, Rafael. A internet é essencial para $82 \%$ das pessoas, diz estudo. INFO Online, São Paulo, maio 2012. Disponível em: <http://info.abril.com.br/noticias/internet/a-internete-essencial-para-82-das-pessoas-diz-estudo-10052012-24.shl>. Acesso em: 28 maio 2012.

FULGENCIO, Paulo Cesar. Glossário Vade Mecum: administração pública, ciências contábeis, direito, economia e meio ambiente: 14.000 termos e definições. Rio de Janeiro: Mauad X, 2007.

GONZÁLEZ DE GÓMEZ, Maria Nélida. Habermas, informação e argumentação. In: PINZANI, Alessandro; LIMA, Clóvis de; DUTRA, Delamar V. (Coord.). O pensamento vivo de Habermas: uma visão interdisciplinar. Florianópolis: NEFIPO, 2009. p. 115-138.

A universidade e a "sociedade da informação". Revista Digital de

Biblioteconomia e Ciência da Informação, Campinas, v. 9, n. 1, p. 225-242, jul./dez. 2011.

GUTIERREZ, Gustavo Luis. Gestão comunicativa: maximizando criatividade e racionalidade: uma política de recursos humanos a partir da teoria de Habermas. Rio de Janeiro: Qualitymark, 1999.

HABERMAS, Jürgen. Consciência moral e agir comunicativo. Rio de Janeiro: Tempo Brasileiro, 1989. 
Brasileiro, 1990.

Pensamento pós-metafísico: estudos filosóficos. Rio de Janeiro: Tempo

A idéia da universidade: processos de aprendizagem. Tradução de João Barreto.

Revista Brasileira de Estudos Pedagógicos, Brasília, v. 74, n. 176, p. 111 -130, jan./abr. 1993.

INTERNET World Stats: usage and population statistics. Disponível em: <http://www.internetworldstats.com/stats.htm>. Acesso em: 28 jun. 2012.

KOTLER, Philip. Administração de marketing. São Paulo: Prentice Hall, 2000.

LIMA, Clóvis Ricardo Montenegro de; CARVALHO, Lidiane dos Santos. Uma abordagem discursiva da avaliação do ensino de graduação em Biblioteconomia no Brasil. Revista EDICIC, Marília, v. 1, n. 1, p. 50-70, Ene./Mar. 2011. Disponível em: <http://www.edicic.org/revista/>. Acesso em: 2 dez. 2012.

LIMA, Clóvis Ricardo Montenegro de; CARVALHO, Lidiane dos Santos; LIMA, José Rodolfo Tenório. Notas para uma administração discursiva das organizações.

DataGramaZero - Revista de Ciência da Informação, Rio de Janeiro, v. 11, n. 6, dez. 2010. Disponível em:

<http://repositorio.ibict.br/bitstream/123456789/132/1/ClovisDatagramazero2010.pdf>. Acesso em: 12 jul. 2011.

MAXIMIANO, Antonio Cesar Amaru. Além da hierarquia: como implantar estratégias participativas para administrar a empresa enxuta. São Paulo: Atlas, 1995.

MIRANDA, Antonio. Biblioteca universitária no Brasil: reflexões sobre a problemática. 1978. Disponível em:

<http://www.antoniomiranda.com.br/ciencia_informacao/BIBLIOTECA_UNIVERSITARIA_. pdf>. Acesso em: 10 nov. 2012.

PAIM, Rafael et al. Gestão de processos: pensar, agir e aprender. Porto Alegre: Bookman, 2009.

PRESTES, Nadja Hermann. Educação e racionalidade: conexões e possibilidades de uma razão comunicativa na escola. Porto Alegre: EDIPUCRS, 1996.

PROJECT MANAGEMENT INSTITUTE. Um guia do conjunto de conhecimentos em gerenciamento de projetos: guia PMBOK. 3. ed. Pennsylvania, 2004.

VALENTIM, Marta Lígia Pomim. Gestão da informação e gestão do conhecimento: especificidades e convergências. Info Home, 2004. Disponível em: <http://www.ofaj.com.br/colunas_conteudo.php?cod=88>. Acesso em: 5 jan. 2013.

VERGUEIRO, Waldomiro; CASTRO FILHO, Claudio Marcondes de; SILVA, Marcia Regina da. Gestão da informação em bibliotecas universitárias: novo cenário e novas competências. In: VALLS, Valéria Martin; VERGUEIRO, Waldomiro (Org.). Tendências contemporâneas na gestão da informação. São Paulo: Sociologia e Política, 2011.

VIZEU, Fabio. Ação comunicativa e estudos organizacionais. Revista de Administração de Empresas, São Paulo, v. 45, n. 4, p. 10-21, out./dez. 2005. 
Racionalidade administrativa e distorção comunicativa nas organizações contemporâneas. In: ENCONTRO DA ASSOCIAÇÃO NACIONAL DE PÓS-GRADUAÇÃO E PESQUISA EM ADMINISTRAÇÃO, 33., 2009, São Paulo. Anais... São Paulo, ANPAD, 2009.

\title{
Title
}

Management discourse: a new perspective for the Brazilian University Libraries

\begin{abstract}
Introduction: This paper presents overview of the university libraries in contemporary society, discussed the basic assumptions related to the administration and revealed discursive forms of administration used in these libraries, published in National Seminar of University Libraries (SNBU).

Objective: Base the administration proposal discourse in Brazilian university libraries, as an alternative to current forms.

Methodology: Investigation of means of administration used in Brazilian university libraries, in contemporary society, published in National Seminar of University Libraries.

Results: Provides general guidance for adoption of management discourse in university libraries.

Conclusion: The administration discourse constitutes an alternative and interesting as possible, consistent with the demands of contemporary society and can contribute to the development of people, the streamlining of organizational learning and innovation.
\end{abstract}

Keywords: Habermas. University library. Library administration. Administration discursive. Theory of communicative action. Discourse ethics.

\section{Título}

Discurso de la gestión: una nueva perspectiva para las Bibliotecas de las Universidades Brasileñas

\section{Resumen}

Introducción: En este trabajo se presenta información general de las bibliotecas de las universidades en la sociedad contemporánea, discutieron los supuestos básicos relacionados con la administración y reveló las formas discursivas de administración utilizados en estas bibliotecas, publicado en el Seminario Nacional de Bibliotecas Universitarias (SNBU).

Objetivo: Base de la propuesta de la administración discurso en las bibliotecas universitarias brasileñas, como una alternativa a las formas actuales.

Metodología: Investigación de los medios de administración usados en las bibliotecas universitarias brasileñas, en la sociedad contemporánea, publicado en el Seminario Nacional de Bibliotecas Universitarias.

Resultados: Proporciona una guía general para la adopción de discurso de la gestión en las bibliotecas universitarias. 
Simone Faury Dib; Clóvis Ricardo Montenegro de Lima

Administração discursiva: uma nova perspectiva para as bibliotecas universitárias brasileiras

Conclusiones: El discurso de la administración constituye una alternativa e interesante posible, en consonancia con las exigencias de la sociedad contemporánea y puede contribuir al desarrollo de las personas, la racionalización del aprendizaje organizacional y la innovación.

Palabras clave: Habermas. Biblioteca de la universidad. La administración de la biblioteca. Administración discursiva. Teoría de la acción comunicativa. La ética del discurso.

Recebido em: 10.09.2013

Aceito em: 30.11 .2013 